\title{
CANADIAN ANAESTHETISTS' SOCIETY SYMPOSIUM ON ANAESTHESIA AND THE ENDOCRINES
}

CHATEAU FRONTENAC, QUÉBEC, P.Q., SUNDAY, JUNE 27, 1971

\section{Programme}

\section{8:00- 8:30 Registration}

8:30 - 8:45 Introduction: Chairman - Raynald Déry

8:45- 9:30 "Influence of Anaesthetics on Neuroendocrine Action"

Leroy D. Vandam, M.D., Professor of Anaesthesia, Harvard Medical School, and Anaesthesiologist-in-Chief, Peter Bent Brigham Hospital, Boston

9:30-10:15 "The Renin-angiotensin-aldosterone System; Primary Aldosteronism; Anaesthesia for the Patient with Arterial Hypertension" Jacques Genest, C.C., M.D., F.A.C.P., F.R.C.P.(c), F.R.S.C., Director of the Clinical Research Institute of Montreal

10:15-10:45 Coffee

10:45-11:30 "Glucocorticoids in Anaesthesia"

Tsutomu Oyama, M.D., Professor, Hirosaki University School of Medicine, Japan

11:30-12:15 "Physiopathology of the Adrenergic System in Anaesthesia and Resuscitation. Therapeutic Implications"

Pierre Huguenard, M.D., Professor and Chairman, CHU HenriMondor, Paris

12:15-13:45 Lunch

13:45-14:30 "Pheochromocytoma and Anaesthesia"

Allen B. Dobkin, M.D., Professor and Chairman, Department of Anesthesiology, State University Hospital of the Upstate Medical Center, Syracuse, New York

14:30-15:15 "The Effects of Anaesthetics on Carbohydrate Metabolism"

Robert G. Merin, M.D., Professor of Anaesthesia, The University of Rochester Medical Center, Rochester, New York.

15:15-15:45 Coffee

15:45-16:15 "The Autacoids in Anaesthesia"

Raynald Déry, Associate Professor, Department of Anaesthesia and Resuscitation, Laval University, Québec

16:15-17:15 Question and answer period 